\section{Representative Meeting}

Annual Representative Meetings of the B.M.A. have the reputation among those who do not attend them of being dull medico-political affairs, with little to do with the dayto-day practice of clinical medicine. At Exeter last week this was not the case. The Representative Body addressed itself to some of those questions upon whose solution depends the future standard of medical care in Britain.

Prominent among these was the present plight of our hospitals-described as undercapitalized, understaffed, struggling against odds to offer patients the kind of service to which they are entitled. Another was how to halt the drift abroad of medical teachers and research workers, a vital group whose loss can ill be afforded. Shortages of all kinds-of trained men and women, money, buildings, equipment-were brought out of their cupboards for airing, but none more likely to wake the public conscience than the grave lack of hospital accommodation for juvenile psychiatric patients. Professional secrecy and alternative, insurancebased forms of medical care, both matters of direct concern to the individual patient, were among other major topics debated.

In the Supplement this week a report of the first four days of the Meeting is given. It includes the debate on the Association's Constitution, held on the first day (p. 18). The remainder of the proceedings, with an important statement on the new N.H.S. superannuation arrangements, will be published next week.

Hospital affairs received close attention. On all sides there was anxiety about the amount of money likely to be available for the development of the hospitals. The diagnosis made in the memorandum from the Central Consultants and Specialists Committee on "The Realities of Hospital Finance Today" ${ }^{2}$ was seen as substantially correct. Despite the Minister's recent reappraisal ${ }^{3}$ of the Hospital Plan now more honestly called a programme, ${ }^{4}$ Representatives were dissatisfied with what is promised, let alone with what has been accomplished. The public was insufficiently aware of the serious crisis facing the hospital service, it was asserted. Only for so long could the devoted service of doctors, nurses, and other workers continue to paper over the cracks in the hospital edifice. A note of economic realism was urgently needed. Where was the logic, one speaker demanded, of patients eating food provided at State expense when the State could not afford to build and equip another hospital to meet the demand for treatment ? The Representative Body, responding to this call for realism, passed by a substantial majority the following composite motion from Gloucestershire and West Sussex:

"That this Meeting proposes that patients in hospital pay a charge for their board, subject to suitable provision for hardship, and that such money be used for the expansion of the hospital services."

It may well take some time for the general public to accustom itself to the simple logic behind this proposition. The suggestion that patients should contribute to their "hotel" charges in hospital will be represented, as it has been already in some quarters, as an attack upon them by a well-paid profession. This is a blinkered view. There is

\footnotetext{
1 Brit. med. F. Suppl., 1966, 1, 217.

2 Brit. med. 7., 1966, 1, 1254. The Hospital Building Programme, Ministry of Health, 1966. Cmnd.
3000 .

- Brit. med. 7., 1966, 1, 1374.

- Ibid., 1966, 2, 68.
}

ample evidence, up and down the country, of public willingness to help hospitals-here money has been raised for a cobalt unit, there for an outpatients department, and so on. And if, as one of the introducers of the motion emphasized, funds so raised are used for local improvements, there will gradually return to the medical scene two casualties of our welfare structure-pride and interest in the local hospital services. These are valuable and dynamic assets. A little self-help would go a long way towards raising hospital morale as well as improving the service more tangibly.

On the second day the Representative Body debated the Association's policy on professional secrecy. By an overwhelming majority (only three voting to the contrary) it confirmed the policy previously laid down by the A.R.M.:

"It is a practitioner's obligation to observe the rule of professional secrecy by refraining from disclosing voluntarily without the consent of the patient (save with statutory sanction) to any third party information which he has learnt in his professional relationship with the patient.

"The complications of modern life sometimes create difficulties for the doctor in the application of the principle, and on certain occasions it may be necessary to acquiesce in some modification. Always, however, the overriding consideration must be the adoption of a line of conduct that will benefit the patient, or protect his interests."

-and affirmed that "the death of the patient does not absolve the doctor from his obligation of secrecy. Where the patient is dead or not in a position to give consent, it is left to the discretion of the doctor to decide who, in the particular case, is the person competent to give such consent." This addition to the previous policy should leave members in no doubt where they now stand.

As was briefly noted last week, ${ }^{5}$ the Representative Body gave its approval for the proposed reform of the B.M.A.'s 63-year-old constitution to go ahead. Although in the end carried by a very large majority, this decision was not reached without a long debate, with a close vote on whether proportional representation (by branch of practice) should apply to the Representative Body itself. The R.B.'s reluctance on this score was understandable, for, in addition to a sizable cut in total numbers, it was being asked to accept a method of election which could result in $35 \%$ of Representatives coming from the hospitals. At present Representatives come predominantly from general practice, although speaking for all branches of practice in their area, so the changes could result in many of today's Representatives losing their seats. However, despite doubts about enough hospital doctors being ready to serve, the R.B. put self-regarding thoughts behind it and in the interests of greater professional unity voted for reform. Next year it will receive for final approval the alterations to the Association's Articles and Bylaws made necessary by its vote.

\section{Complicated Rheumatoid Disease}

The term " rheumatoid disease" was first used by P. Ellman and R. E. Ball ${ }^{1}$ to indicate that the morbid process of rheumatoid arthritis is not confined to the joints. Now, nearly 20 years later, Dr. F. Dudley Hart shows in his Edgecombe lecture, published at page 131 of the B.M.f. this week, how time has supported this concept. Certainly in most patients rheumatoid arthritis begins and remains in the 
joints, but the doctor who sees it as a disease only of joints will miss important complications which may be more treatable than the arthritis. No tissue or organ is immune from such complications, and patients with severe progressive rheumatoid arthritis of long duration are almost certain to develop one or more of them. They may occur before or after the development of signs in the joints.

A. Kay and F. Bach ${ }^{2}$ studied the records of married women who were subsequently to develop rheumatoid arthritis and found them to have been less fertile than matched controls, and there are other ways in which rheumatoid arthritis may "throw a shadow before." Thus pleural effusions, carpaltunnel syndrome, and Raynaud's phenomenon may precede the development of synovitis. W. E. Miall and colleagues ${ }^{3}$ studied a pneumoconiosis in miners with rheumatoid arthritis and confirmed a characteristic appearance on the chest radiograph. The same appearance (Caplan's syndrome) has been found in some miners who had no arthritis at the time but who developed it subsequently.

The best-studied nonarticular manifestations of the rheumatoid process are those which affect the lung. ${ }^{4}$ In addition to Caplan's syndrome the lung may be affected by an interstitial fibrosis with persistent coarse rales at the bases and a tendency to "winter bronchitis" and breathlessness. Occasionally this is severe enough to kill the patient from asphyxia. A nodule in the lung or pleura discovered in a routine chest radiograph, though causing no symptoms, usually commits the patient to investigations to exclude a neoplasm. The frequency with which pleural and pericardial adhesions are found at necropsy suggests that pleurisy and pericarditis are commoner during life than is recognized. Rheumatoid granulomata in the heart may cause conduction defects and valve lesions, though these are seldom severe. Amyloidosis complicates rheumatoid arthritis and may affect the kidneys, liver, gut, and spleen. Considerable enlargement of the spleen, however, is more often a part of Felty's syndrome (splenomegaly, arthritis, and leucopenia). Some patients show striking enlargement of lymph nodes, which may lead to biopsy for suspected reticulosis.

The characteristic nodules of rheumatoid arthritis, usually confined to the elbows, are sometimes found in tendons (which may rupture) or under the heels or buttocks, causing pain on standing or sitting. The secretions of the salivary and lacrimal glands dry up when rheumatoid arthritis is complicated by Sjögren's syndrome, and the eyes may also be affected by a painless episcleritis, or rarely by scleral nodules which may lead to loss of the eye (scleromalacia perforans). Hoarseness may reflect arthritis of the cricoarytenoid joints, ${ }^{5}$ and the patient's hearing may be impaired by disease of the joints between the ossicles of the ear, though large doses of salicylates are a more common cause.

Some of the more distressing and intractable complications result from changes in the medium and small arteries.

\footnotetext{
1 Ellman, P., and Ball, R. E., Brit. med. F., 1948, 2, 816.

${ }^{2}$ Kay, A., and Bach, F., Ann. rheum. Dis., 1965, 24, 169.

- Miall, W. E., Caplan, A., Cochrane, A. L., Kilpatrick, G. S., and Oldham, P. D., Brit. med. F., 1953, 2, 1231.

- Thompson, M., in Progress in Clinical Rheumatology, ed. A. St. J. Dixon, 1965. London.

5 Copeman, W. S. C., Brit. med. F., 1957, 1, 1398.

- Glick, E. N., Proc. roy. Soc. Med., 1966, 59, 555.

' Stubbé, L. T. F., in Salicylates, an International Symposium, ed. A. St. J. Dixon, B. K. Martin, M. J. H. Smith, and P. H. N. Wood, 1963. London.

- Baker, W. M., St Bart. Hosp. Rep., 1877, 13, 245.

- ibid., 1885, 21, 177.

10 Brit. med. f., 1966, 1, 1554.
}

Disease of the arteries to the limbs leads to ischaemic digits and painful ulceration of the legs. Later the blood-vessels in the mesentery may be affected, with the consequence of abdominal emergencies from infarction of intestines. Rheumatoid arterial disease has also been found in the lungs, muscles, heart, kidneys, spleen, and liver. But most commonly arterial disease is accompanied by a severe and often progressive peripheral neuropathy, with foot drop and sensory loss in all four extremities. Patients with mild arterial disease and peripheral neuropathy may recover, but the combination of severe lesions in both arteries and nerves carries a poor prognosis. Some experts believe that arterial disease and neuropathy result from corticosteroid therapy. Those with long memories do not recall seeing them before the era of corticosteroids. Dr. Hart believes that these complications are less frequent with physicians who are wary of prescribing these hormones. Nevertheless, these complications occur in patients never treated with corticosteroids.

Arterial disease and neuropathy of this sort are seldom seen in patients with far advanced rheumatoid arthritis who are confined to homes for the incurable. These are patients whose afflictions have confined them to a bed and chair and whose capacity for locomotion is very restricted. Thus a good case could be made out for assuming that the increased prevalence of arterial disease and neuropathy might well be due to the success of modern therapy in keeping patients from becoming bed-ridden despite their disease. E. N. Glick $^{6}$ has reviewed some of the evidence which suggests that the morbid anatomy of rheumatoid arthritis may in part reflect the amount of use to which the diseased joints are put.

Other systemic complications of rheumatoid arthritis may more properly be regarded as complications of therapy. For example, what used to be known as the " anaemia of rheumatoid arthritis" would seem in many instances to be an anaemia due to loss of iron from repeated micro-haemorrhages from the gastrointestinal tract caused by long-term aspirin treatment. ${ }^{7}$ The chronic pyelonephritis frequently found at necropsy in rheumatoid arthritis may reflect previous years of therapy with drugs containing phenacetin. Corticosteroid osteoporosis leads to the misery of repeated crush fractures of the spine, and corticosteroid dermal atrophy to painful oedema of the legs, with a thin papery epidermis constantly breaking down as a result of the smallest trauma. Corticosteroids, like nearly all the effective antirheumatic drugs, cause dyspepsia and even peptic ulceration.

There are also complications which reflect mechanical changes in the joints from the chronic swelling. Morant Baker $^{8}{ }^{9}$ described the various chronic synovial cysts which may be found near swollen joints, but particularly in relation to the knee. As he noted, these cysts may burst under pressure, so as to communicate directly with the tissue spaces. Acute rupture of a swollen knee into the calf produces a characteristic syndrome of transient redness, tender swelling, and a positive Homans's sign, easily mistaken for acute deep venous thrombosis. Tenosynovial swelling at the wrist may compress the median (and sometimes the ulnar) nerves. Synovial swellings or cysts in relationship to the elbows and knees may also compress neighbouring nerves. Disease of the atlanto-axial joint and the upper cervical spine may lead to subluxations in the neck, which in turn can cause pressure on the spinal cord and nerve roots. Finally, it is worth noting that rheumatoid arthritis is more often associated than would be expected with thyroiditis, pernicious anaemia, haemolytic anaemia, thrombocytopenic purpura, and other diseases which are commonly classified as autoimmune. ${ }^{10}$ 